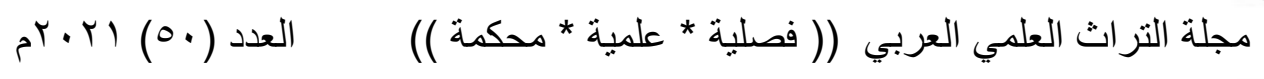

\title{
مفهوم الجمال عند الجاحظ
}

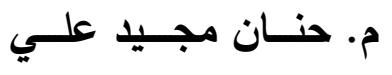

جامعة بغداد - كلية التربية للبنات

Hanan.M@coeduw.uobaghdad.edu.iq

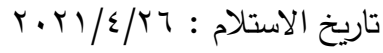

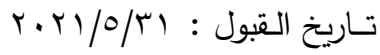

$$
\begin{aligned}
& \text { الملخــص }
\end{aligned}
$$

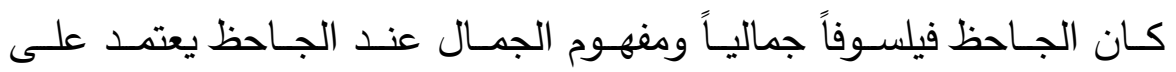

الموضوعية والتركيز على فكرة الاعتدال والتوسط ووضـع فلسفة الادب الجمالي تحت عنـاوين الفصـاحة والبلاغـة والثـعر والخطابـة. وأثـار الى ان الجمـال هو مـا يكون الجمال الطبيعي الذي نراه في الطبيعة والذي يتجلى لنا فيما خلق الله من حولنا من سماء وارض وبشر ونبات وشجر وهو الجمال الذي ابداعه الله وهناك جمال اخر من ابداع الانسان يتمثل فيما نسّميه الفنون الجميلة كالأدب والموسيقى والتصوير والنحت. واشـار الجاحظ الى اللذه الجمالية والتقويم الجمالي الذي يكون من خـلال تذوق الجمال من خلال رؤية جمال طبيعة، شعر، موسيقى، ويكون من خلاله الثعور باللذه الجمالية عند التذوق الجمالية ردة فعله واضحاً جداً عند الانسان المتذوق.

الكلمات المفتاحية، النظرية، الجمالية، الجاحظ. 
The conception of beauty according to Jahiz Msc.Hanan Majeed Ali

University of Baghdad-college of education for girls Abstract:

Al-Jahiz was an aesthetic philosopher, and the concept of beauty for $\mathrm{Al}$-Jahiz depended on objectivity and focus on the idea of moderation and mediation and put the philosophy of aesthetic literature under the titles of eloquence, rhetoric, poetry and rhetoric. He pointed out that beauty is what is the natural beauty that you see in nature, which is manifested to us in what God created around us from heaven, earth, humans, plants and trees, and it is the beauty that God created. Aesthetic pleasure and aesthetic evaluation which is through a person's taste for the beauty of nature, poetry and music, and through which the feeling of pleasure is felt. When tasting the aesthetic, his reaction is clear to the person who tastes beauty.

Keywords: theory ,AL-jahiz ,beauty, 


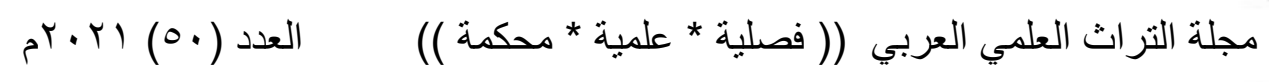

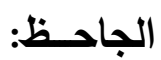

هو عمرو بن بحر بن محبوب بن فزارة الكناني البصري المكنى بابي عثمان، وكان ثمة نتوء واضح في حدقتيه فلقب بالحدقي ولكن اللقب الذي الصق به كثيراً وأشتهر به هو الجاحظ لجحوظ عينيه وتاريخ ولادته هو . 7 أه أما وفاته كانت في

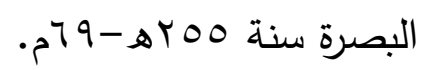
الجاحظ موسوعة علمية لان ثقافته اشتملت على العلوم المعروفة كافة في عصره فدرس المنطق والفلسفة والرياضيات والطبيعيات والاخلاق وكتب عن الادب والثعر

وابدع فيها جميعاً. (1)

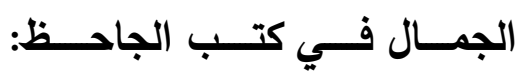

لا نجد نظريـة جماليـة اصيلة الا عند الجاحظ، وربمـا سـاعده على ذلك موهبته الأدبية وقد جمع الفلسفة والفن في نتاجه وطبق أصول نظريتيه في اثاره على نحو ممتاز يسترعي الانتباه، ويدفعنا الى التسـاؤل عما اذا كان الجـاحظ استتبط أصسوله الفنية من نتاجه أو صاغ نتاجه بعد أن وضع اصوله الفنية. وإذا نظرنا إلى الكتب التي شرح فيها نظريته الجمالية مثل الحيوان والبيان والتبيين نجدها قد وضعت في أواخر حياته مما يحدونا بالقول انه استخرج أصوله الفنية من نتاجه. وعندما حاول الجاحظ تحديد الجمال وجد صـعوبة دفعته إلى القول "أن أمر الحسن أدق وأرق من أن يدركه كل من أبصره"(؟). 
وكتابه البخلاء يستحق بجدارة ان يكون تحفة من تحف الادب العالمي عبر التاريخ وليس كتبه الاخرى قليله القدرة ولكن كتاب البخلاء استثناءاً عالمياً، ابدع الجاحظ في هذا الكتاب بطريقة مدهثة معنى المعايشة الجمالية وقيمتها في هذا الكتاب. وهذا يعني أن ادراك الجمال لا يتم بوساطة البصر فقط وأنما يحتاج إلى أعمال الفعل والثقافة والرياضة والخبرة. الجمال بنظر الجاحظ هو التمام والاعتدال او هو صفة الجسم التآم الأجزاء المعتدل التكوين: إن الأجزاء التي تدخل في تكوين الجسم ينبغي ان لا تتجاوز المقدار من حيث الحجم فلا تكون مفرطة الكبر أو الصغر • وبالنسبة للجسم البشري تكون الزيادة في طول القامـة او سعة العين او الفم نقصـاً في الجمال وان عدت زيـادة في الجسم والاعتدال يعني التوازن والتتاسب بين أعضاء الجسم، وبالنسبة للجسم البشري ينبغي أن يكون ثمة تناسب بين الرأس والجذع والأطراف، وبين العينين والاذنين والأنف والفم والذقن والجبين. فالظهر الطويل لا يتناسب مثثلاً مـع الفخذين القصيرين. وكذلك لا يتلاعم الظهر القصسير مـع الفخذين الطويلين وقل الثـيء نفسـه بالنسبة لسعة الفم والعينين بالقياس مع سعة الوجه وحجم الرأس. ما هو المقياس الذي عظم أعضـاء الجسم ونحكم عليها بأنها تامسة معتدلة ومن ثم جميلـة؟ يجيب الجـاحظ ان ذلك المقيـاس هو الجسم المتوسط المعتدل التكوين فمـا

$$
\text { أقترب منه عد جميلاً وأما ما ابتعد عنه عد قبيحاً. }
$$

ويطبق الجاحظ أصول الجمال هذه على الانسان فيقول ان الشخص الجميل هو الانسان المتناسق الاعضاء. والمتوسط مابين السمنة والنحافة ولابد فيها من جودة القد 


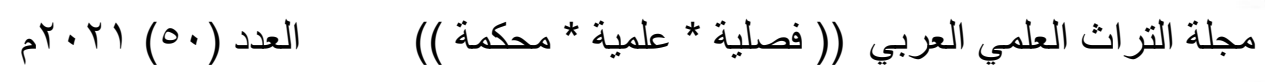

وحسن الخرط واعتدال المنكبين واستواء الظهر ولابد من ان تكون كاسية العظام بين

الممتلئة والنحيفة(r).

ان الانسان الجميل هو الذي يكون معتدل الأعضـاء لا تزيد أعضـاؤه عن الحد في

الضـخامة، وتتتاسـب فيمـا بينهـا فيخــو جسـمه مـن الفضـول، ويكـون بـين الجسيم

والمشوق ويعتدل منكبيه ويستوى ظهره ويحسن قده. وهذا التركيب يجعله يتثنى في

مشيته فيستهوي القلوب ويغلب الابصار .

ونستطيع ان نوجز الأصول التي بنى عليها الجاحظ نظرته الى الجمال بما يأتي: ا ـ الجمال موضوعي أي قائم في الأشياء، وليس امراً ذاتياً. r. يدخل في تقويم الأشياء، من الناحية الجمالية، الحس والعقل معاً.

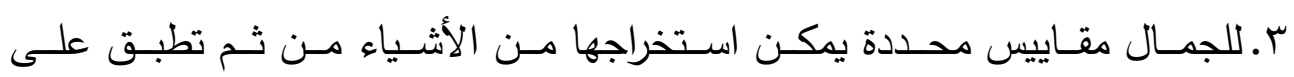
الموضوعات التي نريد الحكم عليها(؛). ع.لم يهتم الجاحظ بالناحية الروحية في الجمال واقتصر على الناحية المادية الجسمية فهو مثلاً لم يتلفت في كلامهه عن جمال المرأة الى نفسيتها وأخلاقها وأنصب اهتمامه على صفاتها الجسمية. ه. ان مفهوم الجاحظ للجمال يشباه مفهوم ارسطو فهو يقوم على فكرة الاعتدال او التوسط والتتاسب(0) الى جانب هذا الجمال الطبيعي الذي ابدعـه الله يوجد الجمال الفنـي الـذي أبدعـه الانسـان والـني يتمثل في الفــون الجميلـة مـن نحـت وتصـوير وموسيقى وأدب وغيرها. ولم يهتم الجاحظ من هذه الفنون الا بفن الادب فتكلم عن البلاغة والخطابة والشعر وطبق الى حد بعيد الأصول التي مر ذكرها للجمال. 
والبلاغة هي أبلاغ المعنى الى السامع بوساطة الكلام. هذا الكلام ينبغي أن يكون فصيحاً أي واضحاً حسناً. واللفظ الفصيح هو الذي يقع وسطاً بين السوقي والغريب فالقصد من ذلك أَن تتجنب السوقي والوحشي ولا تجعل همك تهذيب الألفاظ، وشغلك في التخلص الى غرائب المعنى وفي الاقتصـاد بـلاغ وفي التوسط مجانية وخروج عن سبيل من لا يحاسب نفسه (T) ان المقاييس الذي ينبغي اللجوء اليها لمعرفة توافر الفصاحة في الكلام هو القرآن ولغـة الاعـراب وأمـا كـلام العامـة وأهل الأمصـار فليس حجـة في الفصـاحة. والجدير

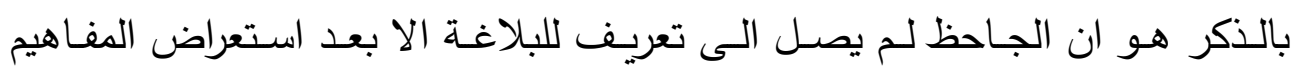
المختلفة لها التي وجدها عند الفرس واليونـان والهنود والعرب. أقاموا البلاغـة على أصلين هما الايجاز والطبع والايجاز هو حذف ما فضل في الكلام والطبع هو مجانية التكلف والصنعة (v). لــ يتبن الجـاحظ الأصـل الأول للبلاغـة أي الإيجـاز وانمـا أثر فيـه المسـاواة أو تفضيل الالفاظ على اقدار المعاني. وذلك انسجاماً مـع الفلسفة الوسطية التي نـادى بها، وقد شرح مبدأه هذا قائلاً: "وانما وقع الهذي على كل شيء جاوز المقدار، ووقع اسم على كل شيء قصر عن المقدار، فالعي مذموم والخطل مذموم"(^). واذا أريد في الايجاز أن يعتمد شرطاً من شروط البلاغة وجب الا يكون مرادفاً للاختصار كما كان يفهم في عصره بل يجب ان يعني حذف ما فضل عن المقدار. 
والمقدار هو كمية اللفظ اللازمة للتعبير عن المعاني بوضوح، ينبغي أذاً إن يحذف من الكلام ما لا يكون سبباً ولا يردد ويكتفي في الافهام شطره فما فضل عن المقدار فهو الخطل. وبناء على هذا لا تعد الاطالة خطلاً إذا جاءت في موضعها أي إذا كانت ضـرورية لإيضـاح المعنى وكذلك لا يعد الإيجاز عجزاً اذا كان في موضـعه، أي إذا

كان كافياً لايضاح المعنى (9). واذا كـان الجـاحظ يـرفض الأصـل الأول للبلاغـة العربيـة أي الايجـاز ، فانـه يتبنى الأصلي الثاني أي الطبع ويؤيده بقوة لأنه يتفق مع فلسفته الطبيعية فهو يعد الأدب الاب وليد الطبع وليس صناعة متكفلـة ويقول إن النثر أو الثعر الذي تعود بـه الطبيعـة وتعطيه النفس سهواً رهواً مع قلـة لفظه وعدد هجائه أحمد مرامـا وأحسن موقعاً في القلوب وأنفع للمستمعين من كثير خرج بالكد والعلاج لأن التقدم فيه وجمع النفس لـه وحصر الفكر عليه لا يكون إلا ممن يحب السمعة ويهوى الاستطالة(·'). اذاً الجاحظ وضع مقاييس واوزان خاصة للبلاغة العربية جعل منها منطلقاً لأظهار الجمال في الادب الفني من خلال تطبيق شروط الالتزام والتتسيق والتنظيم في الفنون الادبية لاظهار الصورة الجمالية. والطبيعة تقتضي الواقعية او محاكاة الواقع بصدق دون تحوير او تزوير حتى نرى أن الجاحظ يذهب في ذلك أبعد مدى فيزعم أن الواقعيـة تقتضـي ايراد الالفاظ كمـا وردت على السنة أصحابها من دون لحن فيها اذا كانوا من الفصحاء.

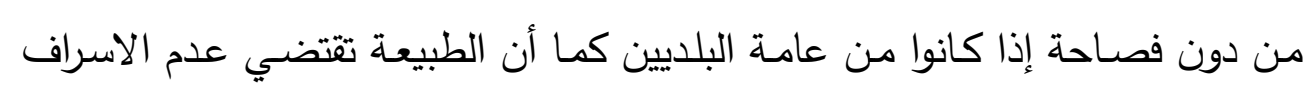
في التتقيح والتصفية لأن ذلك يؤدي الى التكلف وعسر الفهم ويقول في ذلك: "وليس

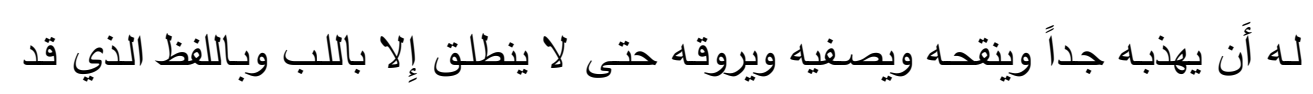


حذف فضوله (")، وأسقط زوائد حتى عاد خالصاً لا شوب فيه، فإنه أَن فعل ذلك لم

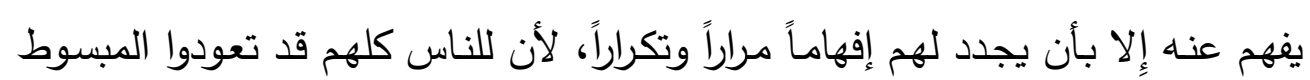

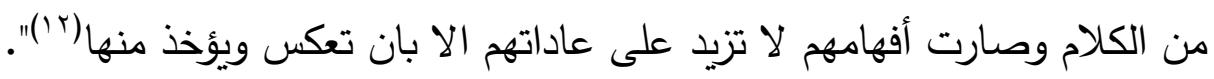

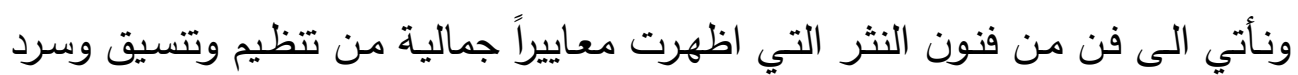
منظم وهذا بحد ذاته جمالاً فنياً وهي الخطابة.

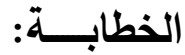

الخطابة طبع يولد مع بعض الناس ولا يكتسب اكتساباً وفي هذا لا يخرج الجاحظ

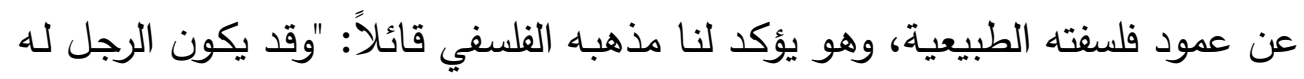
طبيعة في الحساب وليس له طبيعة في الكلام، وتكون له طبيعة في التجارة وليس له

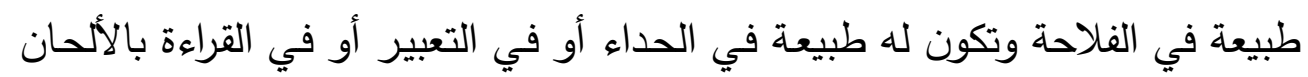

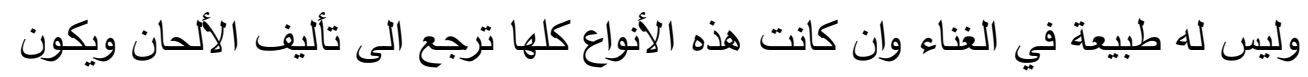

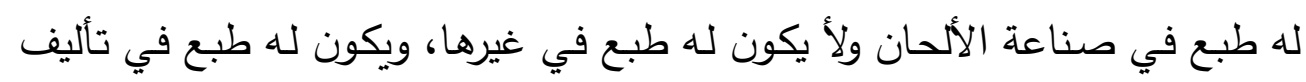
الرسائل والخطب ولا يكون له طبع في قرض بيت الثعر ومثل هذا كثيراً جداً (r').

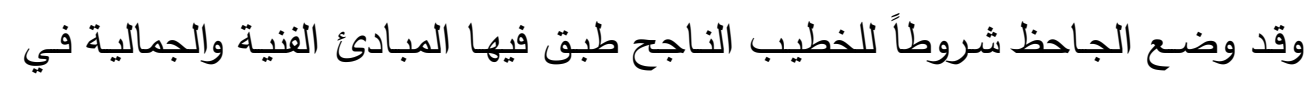

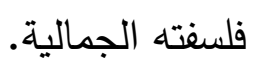
ويتحدث الجاحظ مطولاً عن سنن الخطابة فيرى في التمكن من اللغة أهم شرط في الخطيب الناجح، وهو يقول إن اللحن في الخطيب عيب لا يغطى وذنب لا يغتفر ومن آلة الخطابة في نظره جهارة الصوت وحدة النبرات ليتمكن الخطيب من إيصال

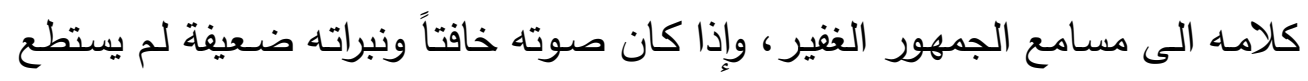
التأثير في مستمعيه. 
ومن سنن الخطابة ايضاً قلة الإشارات والحركات عند الالقاء لان كثرة الحركات دليل على العجز يلجأ اليها الخطيب عندما يعوزه البيان وحجة اللسان فضلاً عن الى جمال هيأة الخطيب وسمو اخلاقه، فانهها شديدا التأثير في المستمعين وشتان بين خطيب ذميم المنظر منحط القيم المعنوية وبين اخر بهي الهيأة مرتفع المعنويات(؛ (). امـا أصول الخطبة ذاتها صنيع فني فقد طبق فيها الجاحظ مبادئه الفنية والجمالية. والأصل الأول الذي ينبغي مراعاته دائهاً هو ملاءمة الكلام لمقتضى الحال، أي حال المستعصمين ومستواهم التقافي والاجتماعي وظروفهم النفسية والمعيشية. والاصـل الثاني هو التقيد بالموضـوع وعدم الخروج عنـهـ لان من شـأن الخروج مـن الموضوع تشويش أفكار المستمعين ومن أصول الخطابة الابتعاد عن الألفاظ الغربية لان الاكثار منها يجعل المعاني عسيرة الفهم ويحول دون تحقيق الخطبة الغاية التي القيت من أجلهاُ هي الاقناع والتأثير . أن ألفاظ الخطبة ينبغي أن تتصف بالفصاحة والجزالة والجمال لتسترق الأسماع وتهفو لها النفوس ومن سنن العرب بدء خطبهم بالبسملة والحمدلة والتصلية والخطبة التي تخرج عن هذه السنة تدعى بتراء(10). اذاً هذه الاصـول التي وضـعها الجاحظ تجعل مـن الخطبة صـناعة فنيـة طبق فيها شروط المبادئ الفنية والجمالية في العمل الادبي. ومن سننهم ايضاً توشيح الخطب أية من القرآن الكريم والخطبة التي تخلو من القرآن تدعى الثوهاء. وكذلك من عاداتهم ايراد شواهد حكمية وشعرية في خطبهم تأييداً للأفكار التي يريدون ابلاغها الى المستمعين واقناعهم بها. ولم يتوقف الجاحظ طويلاً أمام مسألة تصنيف الخطب كأرسطو وانما أشار أشارات عابرة الى أنواعها فقال ان من الخطب ما تكون 


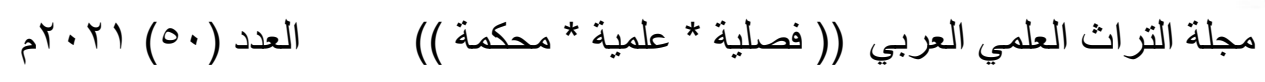

قصيرة وما تكون طويلة ومن أنواع الخطب خطبة النكاح وخطبة العيد وخطبة اصلاح ذات البين.

ويبدو إنـه لم يكن مطلعـاً على كتاب الخطابـة. ومـع ذلك نـراه يقارن بين الموهبة

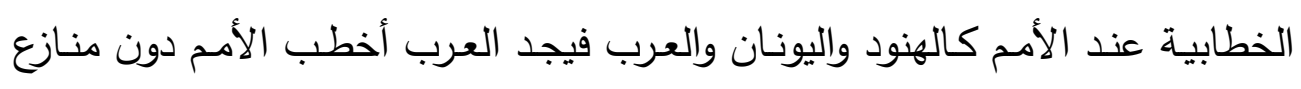
لانهم أصحاب طبع قوي لم يكتسب بالتعلم والرياضة ولا يحتاج العربي الا الى توجيه

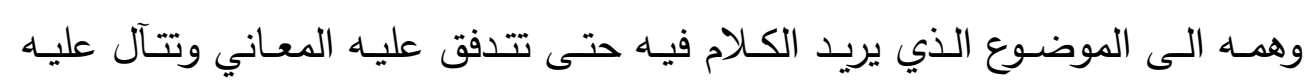
الالفاظ(17). (17).

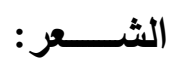

التحديد الذي يعتمده الجاحظ للثـعر هو " الثـعر صـناعة وضرب من النسيج وجنس من التصوير" (1) (1). فالجاحظ يؤكد على أن الثعر طبع أو موهبة حباها الله قلة من الناس. ولا يقوى

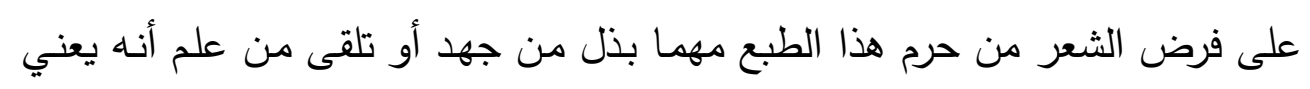

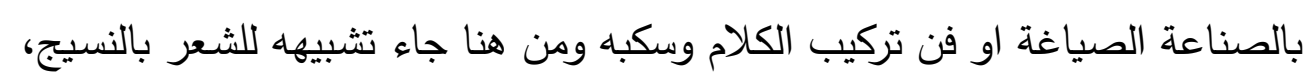

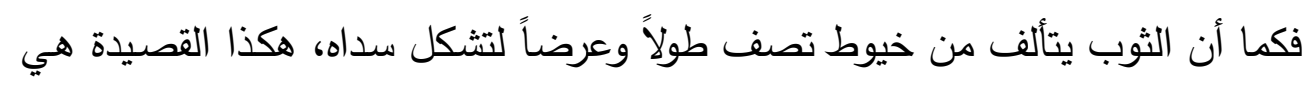
مجموعة أبيات مؤلفة من وصف ألفاظ تثكل الصنيع الفني الرائع (^). والثعر ضرب من التصوير ، وفي هذا إثارة الى أهمية عنصر الخيال في الثعر .

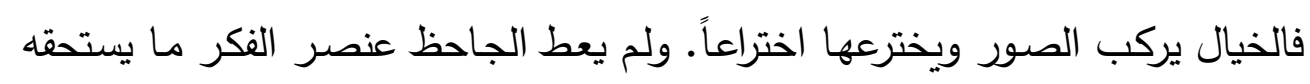
من أهمية لأنه يعد المعاني مطروحة في الطريق يعرفها جميع الناس وكذلك أهمل

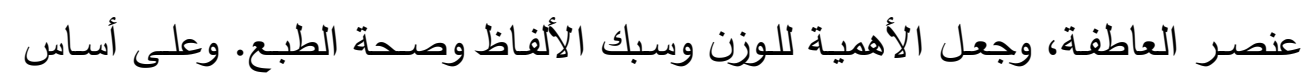

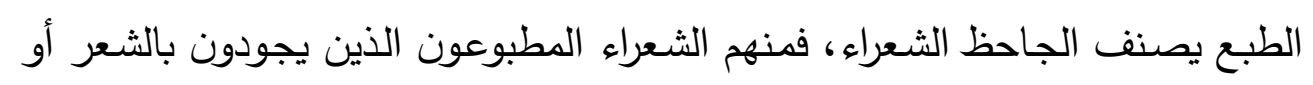
$\varepsilon v$. 
تفيض بـه فرحتهم ولا يتكلفون فيه صنعه أو يهتمون بتصفية وتتقيح، ومنهم الثـعراء المتكلفون الذين يعتنون بتنقيح شعرهم وإعادة النظر فيه لياتي أجود واصـح. وتكلم الجاحظ عن نشأة الشعر العربي، فزعم إنه حديث الميلاد نشأ قبل الإسلام بنحو قرنين من الزمن، وقد تأخر ظهوره عن الفلسفة اليونانية التي تمثلت بكتب أفلاطون وأرسطو

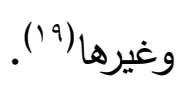

وأشـار الجاحظ الى ظـاهرة أخرى في الثـعر هي قضية نحل الثعر التي أثارت ضـجة كبرى في العصـر الحديث لقد عمد بعضههم إلى أشعار نسبوها إلى شعراء سبقوهم في الزمن ولذا يدعوا الجاحظ إلى عدم تصديق كل ما يروى لأن الكذب كثير

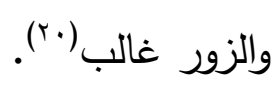

وتصدى الجاحظ لظاهرة ثالثة هي الثعر المولد وقيمة هذا الثعر بالنسبة للشعر القديم. وقال أن الفرق بين الصنفين يعود إلى أن الثعراء القدامى نظموا الثعر عفواً من دون تفكير وكد ذهن، بينما نظم المولدون الثعر وأدخلوا فيه الثقافة التي حصلوا عليها في بيئتهم المتحضرة عندما انتشر العلم وترجمت الكتب الأجنبية إلى العربية من علم وفلسفة وأصبح الثاعر مثقفاً ولم يعد امياً(r). يبين الجاحظ أن الشعراء القدماء كان الشعر عندهم موهبة وارتجالاً ولكن الشعراء المحدثين ادخلوا التطور في شعرهم حيث الثعر لديهم يمر بمرحلة التظيم والترتيب اما قديماً كان دون تتظيماً او ترتيباً.

ويعالج الجاحظ مسألة طريفة هي دور الوراثة في الثعر وينتهي بعد دراسة الثعر في عدة قبائل وعدة أقطار الى ان الوراثة والتربية والمناخ وطرق العيش لا علاقة لها بالثاعرية لان الشعر هبة من الله(rr). 


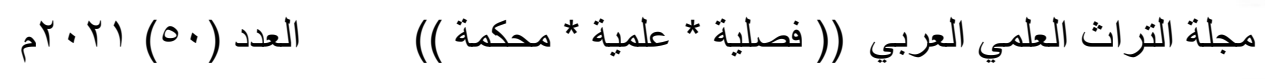

وأشار الجاحظ الى مسألة الوراثة في الثعر وبين أن الثعر لا يورث ولا يعطى لأحد لأنه موهبة من الله. ويتحدث الجاحظ اخيراً عن قيمة الثعر ومدى تأثيره، ويتساءل عما اذا كانت له له لهانه

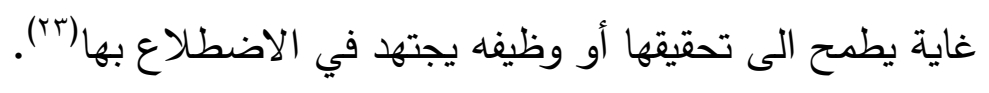
فيلاحظ ان للشعر فائدة للمدوح - إذا كان مدحاً لأنه يخلد ذكره وفائدة للثاعر فهو يظهر عبقريته ويعود عليه بالرزق

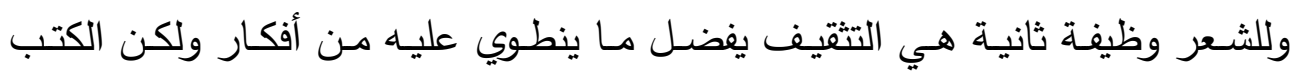
المنشورة أعم نفعاً من هذه الناحية لأن النثر، أقدر على نقل المعارف من الثعر .

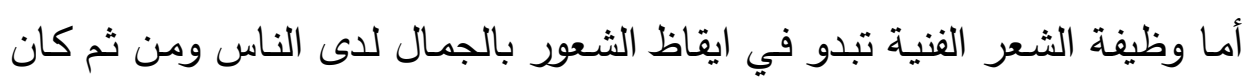
للثعر ذلك الوقع الساحر في النفس، وقد عبر عنه "أن في البيان لسحراً".

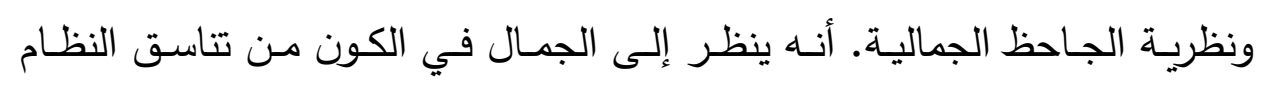

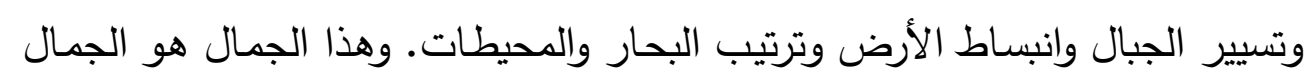
الذي أبدعه الله. ان الله سبحانه وتعالى خلق الكون وما فيه من سماء وأرض وانهار ـ وأكرم الانسان بالخلافة في الأرض وخلق الانسان في احسن تناسق.

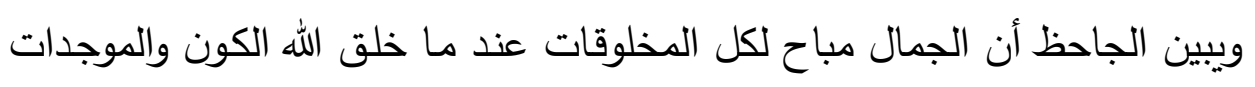

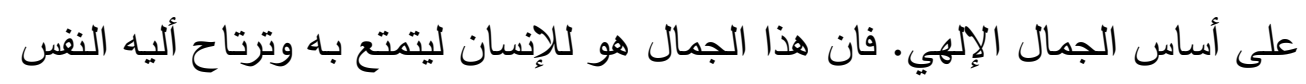

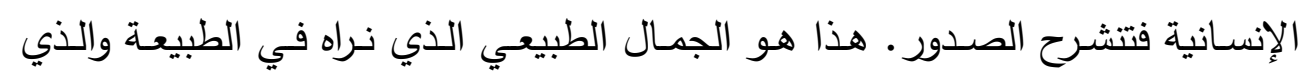

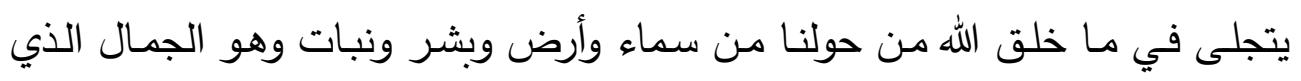




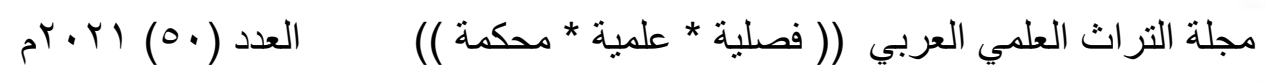

أبدعـه الله وهنـاك جمـال أخـراً مـن ابـداع الانسـان يتمثل فيمـا نسـيه الفنون الجميلـة كالآدب والموسيقي والتصوير والنحت (؟؟).

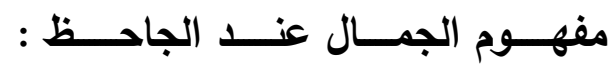

ويرى الجاحظ أن السبب الرئيس وراء طلب الجمال هو المتعـة التي يحركها في النفس ولا فرق بين الجمال الطبيعي والجمال الصنعي يقول فيما كان جميلاً حسناً من الكـلام "فإذا كانـت الكلمـة حسـنة اسـتمتعنا بهـا على قدر مـا فيهـا مـن الحسـن (ro)" ويضيف فائدة أخرى هي أن المتعة واللذة الجمالية تزداد وتنقص تبعاً لدرجة الجمال التي يحملهـا الموضـوع وهـا حكم حـد مستحسـن لان مـا يشـنا ويجذب انتباهنـا، ويستوقفنا من خضم الكثرة الكاثرة من الموضوعات الجمالية(بr) عندما يقف المـره متأملاً أمـام منظر طبيعي خـلاب مثل بضـع شـيرات تثـابكت أغصانها مظللة بينبوع ماء او يشاهد قوس قزح أو يسمع ضرب من الموسيقى يشعر الموسيقى تراقص روحه طربـاً او تستمد نسيج انغامها مـن أحاسيسـه أو يقرأ روايتهـ بتروي الرؤوم شغف المشوق فلا يلبث أن يجد نفسه وكأنه أحد شخوص الرواية يفرح لفرحهم ويستاء لإستيائهم، وربما تأخذه النشوة حيناً فيهم بالتدخل وتغير الحدث ولكن

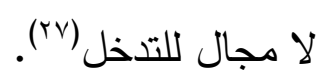
لذلك عندما حاول الجاحظ تحليل الجمال وما يتركه في نفس القارئ في بادئ الامر إلا أن يقف عند الأطر العامـة لهـا مـن جهـة ضـرورة اتسـام الموضـوعات المعايشـة بالجمالية وخلوها من التعقيد وما يعسر عملية المعايشة على العموم فإذا كانت كذلك كانت سريعة النفاذ الى القلوب واتحدت وتمازجت مع كينونة الإنسان ولذلك فإن مثل هذه الموضسوعات هي التي تشتهر ويطالبها الطالبون ويستفيد منها المتعلمون وفي 
ذلك يقول: "متـى كـان اللفظ كريمـاً في نفسـه متخيـراً في جنسـه وكـان سـليماً مـن الفضول، بريئًا من التعقيد حبب إلى النفوس، واتصل بالأذهان والتحم بالعقول وهشت إليه الأسماع وارتاحت له القلوب وخف على ألسن الرواة وشـاع في الافاق ذكره وعظم في الناس خطره وصار ذلك مادة العلم الرئيس ورياضة للمتعلم الريض(^)")". اذاً تذوق الجمال يؤثر في الانسان فيثير الجمال في نفس الانسان البهجة والسرور والرضى سواءً كان جمال طبيعة او جمال شعر أو جمال مقطوعة موسيقية فتحدث اللذة الجمالية في النفس البشرية.

وصف الجاحظ الأثار التي تظهر في اللذة الجمالية وجدانها تتجلى سروراً وغبطة وربما تتحول إلى رقص والرقص هو الحركات الإيقاعية المتناسبة مـع النشوة، ويتخذ للدلالة على ذلك من الصوت انموذجاً يقول: (أمر الصوت عجيب وتصرفه في الوجوه أعجب فمن ذلك أَن منه ما يقتل كصوت الصاعقة ومنها ما يسر النفوس حتى يفرط عليها السرور فتعلق حتى ترقص (rq) مثـل الأغـاني المطربـة والقـراءات الملحنــة واسـتغلت النـاس هـذه السـمة الملازمــة للأصوات الموسيقية فصارت بالأصوات تتوم الصبيان والأطفال. وأنّ القيم الجمالية متعددة ومتنوعة بتنوع الأفراد في تحسسهم للجمال فمنهم من يراه ذاتياً ومنهم مـن يـراه موضـوعياً ومنهح من يجهـع بين الذاتيـة والموضـوعية وإشكالية الجمال التي كانت محل اهتمـام الفلاسفة القدامى - خاصـة اليونـانيين منهم - يجيب عنها الجاحظ إجابة يجمع فيها بين التوظيف الإستدلالي العقلي والنص النقلي وتحقيق المواءمة بينهما بما ينبئ أن القيم الجمالية تحتل الريادة بين القيم الأخرى لما لها من تعدد في المظاهر واتساع في الأفق ومقدرة على مغايرة القيم الاخرى(·r). 
اذاً الذات التي تقوم بأطلاق الاحكام القيمية الجمالية على الموضوع لا تخلو مما يؤثر

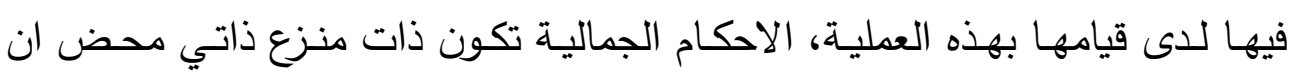
يستمد احكامـه مـن الـذات، والحكم الموضـوعي يكـون للشكل لحامـل للخصـائص الجمالية دوراً في اصدار الحكم الجمالي. فالفعل الجمالي لا يرقى بمضمونه فحسب ولا بشكله فقط بل بشكله ومضمونه في آن

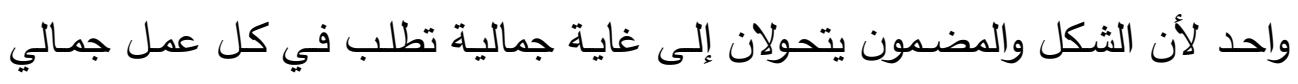

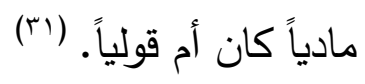
أنّ الجمال واقع في مجال الخير والحق ولا ينجم عنه الا النفع والسرور مادياً وروحياً. وقد يكون الجمال فكرياً متى ارتبط بالحق قيمة مثلى يطلبها بتزكية من قوى الخير الموجودة في الوجدان. فالوجدان غايته الجمال وهناك ثلاثة أنواع من الجمال، هي: 1- الجمال الجسماني وهو طبيعة القيم المادية التي ندركها وتكون مادة الفن مباشرة. ץ- الجمال العقلي وهو من طبيعة القيم التي يعمل فيها الفهم والعقل دون اهمال للمنطق الحسي الذي تنطلق منه. r- الجمال الأخلاقي من طبيعة القيم الروحية يدرك بالضمير (rr).

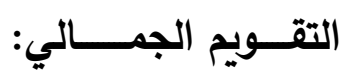

يتوافق التقويم الجمالي على نحو خاص مع طبيعة الجمال أو حقيقته وتمظهره في الثكل الذي يحمله هذا إلى جانب معطيات المعايشة الجمالية.

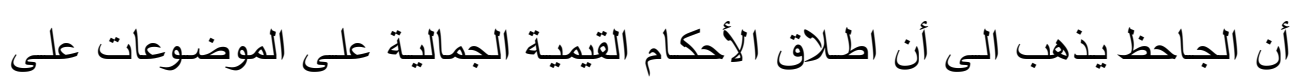
اختلاف مراتبها وتباينها. أمر مرتبط بوثاقة مع مجموعة من المعايير يمكن إجمالها فيما يأتي: 


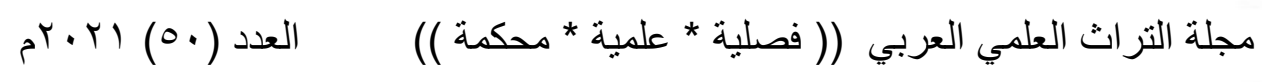

ا- يستمد الموضوع قيمته الجمالية بالدرجة الأولى من الاعتدالية والتتاسب في آن

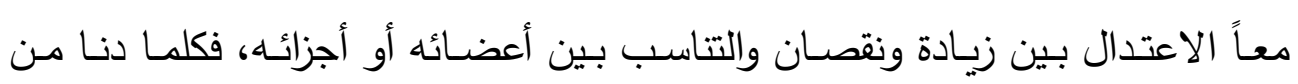
الاعتدال أكثر كان متسماً بقيمـة جمالية أسمى وإذا حقق الحسن أو الجمال معادلة

التوازن والاعتدال اتصف بالجمال(rrr).

ץ- أولى الجـاحظ الشكل الحامـل للخصـائص الجماليـة دوراً بـارزاً في اظهار قيمـة جمالية محددة على الموضوع وهذا يظهر في قوله "والتاج بهي، وهو على رأس الملك

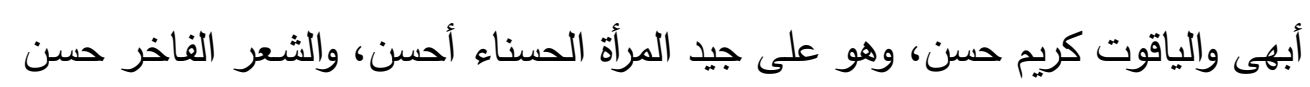

$$
\text { وهو في فم الأعرابي أحسن"(گ؟). }
$$

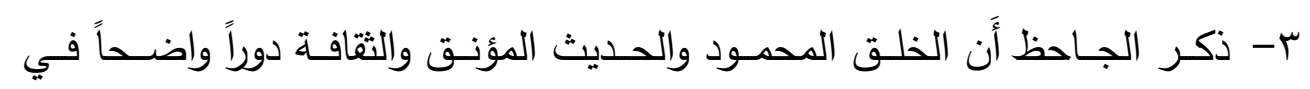

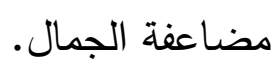

ع- ان الذات التي تقوم بإطلاق الحكم القيمي الجمالي على الموضوع لا تخلو هي

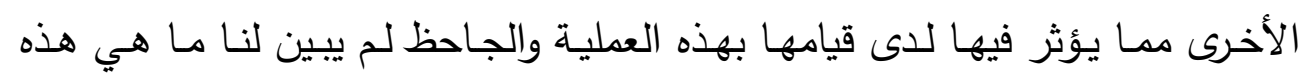
العوامل ولم يشر إليها، ولكنه كان في بعض أحكامه الجمالية ذا منزع ذاتي محض، بمعنى انـه يستمد أحكامـه القيمية مما تمليه عليه الذات وبغض النظر عما يتمتع بـه الموضوع من قيمة جمالية. (ro). اذاً يتوافق التقويم الجمالي على نحو خاص مع طبيعة الجمال وحقيقته وظهوره في ملي الثكل الذي يحمله، هذا الى جانب معطيات المعايشة الجمالية، بما يظهر الجمال في الخلق المحمود، في شعراً جميل، لوحة فنية، جمال طبيعة خلابة، هذه كلها تظهر فيها الصفات الحقيقية للجمال. 
على الرغم ما تنطوي عليه العلاقة بين الاثر الجمالي وجمهور المتلقين يصح على العلاقة بين الفنان والاثر الفني والجمالي من ناحية، عموم العلاقة وعلى الفنان واثره

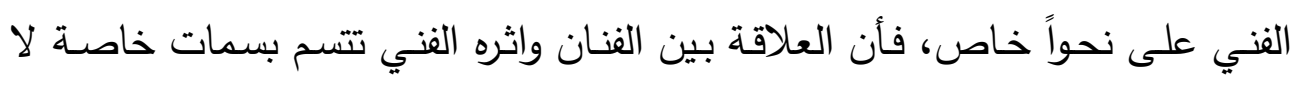
تكون عند اي متلقي مهما كانت صفته ذلك انها في البداية والنهاية علاقة المبدِع والمبدَع علاقة تبدأ منذ الومضة التي تتقدح في الذهن على نحو اشعاع مباغت باهراً قد يكون من المتعذر وصفه وهو ما يمثل ولادة الفكرة مروراً بمراحل نضجها ونمائها

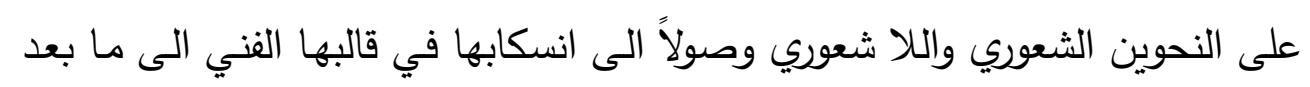

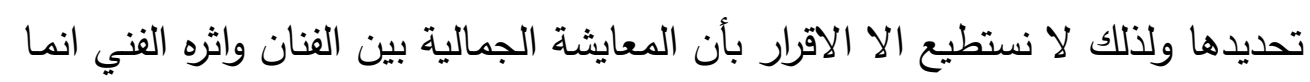
هي معايثة نوعية لا نظير لها بين غير الفنانين.

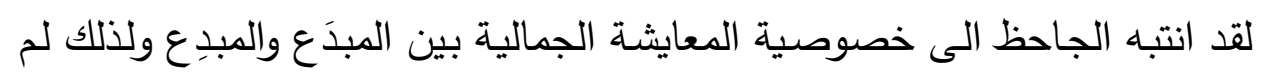

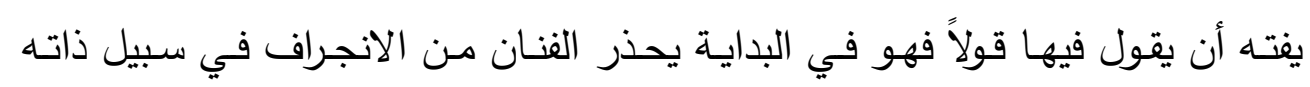

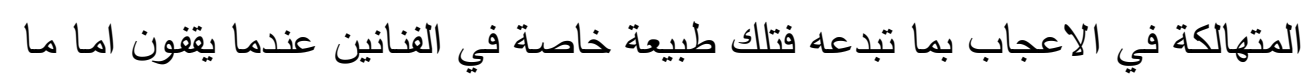

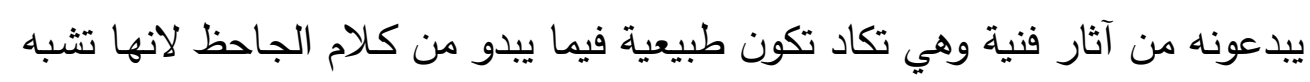

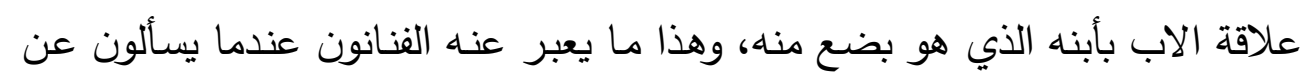
عملهم المفضل بقولهم: "كل أعمالي كأولادي لا فرق بينها عندي". ولذلك يخاطب صاحب البيان الفنان بقوله: "فلا تثق في كلامك برأي نفسك، فأني

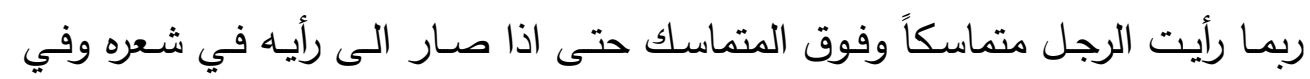
كلامه، وفي ابنه رأيته متهافتاً وفوق المتهافت" (َr). 
اذاً لا يقف الجاحظ عند هذا التحذير بل يعلل ذلك بأعجاب الانسان بثمرة عقله

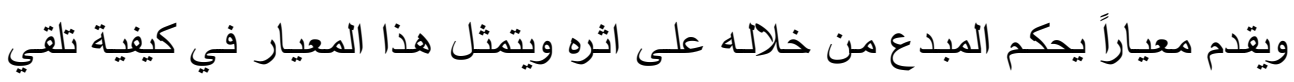
الجمهور وخاصةً المختصون ومدى تقبلهم واستحسانهم له. فالمعايثــة الجماليـة مـن الموضـوعات المهمـة والحساسـة فـي علـم الجمـال وهـو موضوع غني ومتنوع الجهات، ابرع من يتحدث فيه هو ابرع من ان يصنع المعايشة الجمالية الرائعة، ولقد كان الجاحظ من نوادر تاريخ الابداع الخالدة في قدرة على تقديم فن يمتلك احاسيس المتلقي ويفرض عليها التفاعل معهه تفاعلاً مدهشاً وخاصـة كتابه البخلاء وهو تحفة الادب العالمي فقد ابدع في هذا الكتاب بطريقة مدهشة فهو يدرك معنى المعايثة الجمالية وقيمتها ولكن سوء الحظ ان هذا المصطلح لم ينشأ الا متأخراً وان كان موضوع ميدانه قديماً ربما قدم الانسان أو على الاقل قدم الانتاج الفني ومـع ذلك فأن ما جاء به الجاحظ في هذا الصعيد لا يمكن اغفال قيمته التاريخية(؟Y). الخاتمة:

تفاعل الجـاحظ مـع هويتهـه وثقافته العربية والاسـلامية وبدأ ذلك واضـحاً في فكره وادبـه وفلسفته من خـلال اثاره ومضـامينها وعناوينها ولذلك من البداهـة ان نقول ان فلسفته الجمالية وافكاره الجمالية نتاج هذا التفاعل بين هوية الجاحظ الشخصية وهويته المجتمعية.

لقـد حلـق الجـاحظ في اسـتقلاليته في فكـرة الجمـال الاخلاقي والنقدي ومجمـل الموضوعات التي طرحها ذات بصمة اسـلامية وعربية برزت بروزاً واضحاً في عدد من المواضيع ومنها تحديده مفهوم الجمال. 


\section{Conclusion:}

Al-Jahiz's interaction with his Arab and Islamic identity and culture was evident in his thought, literature, and philosophy. The topics he raised, but the Islamic and Arab imprint emerged clearly in a number of topics, including their identification.

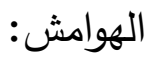

$$
\text { (') كامل عويضة، الجاحظ الثاعر الاديب الفيلسوف، بيروت، صهـ. }
$$

(r) الجاحظ، رسالة القيان، تحقيق عبد السلام محمد هارون ضمن رسائل الجاحظ، القاهرة،

$$
\text { . N1 ص (197 }
$$

(r) الجاحظ، رسالة النساء ضمن اثار الجاحظ، تحقيق عمر أبو النصر، مطبعة النجوى،

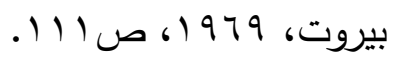

عُعي ابو ملحم، في الجماليات نحو رؤية جديدة الى فلسفة الفن، الطبعة الاولى، بيروت، وبل،

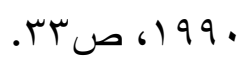

•علي ابو ملحم، في الجماليات نحو رؤية جديدة الى فلسفة الفن، الطبعة الاولى، بيروت، ( - 2)

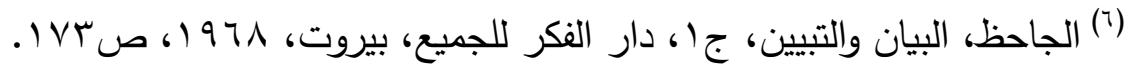

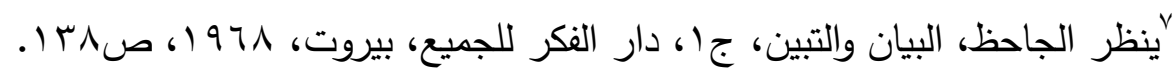

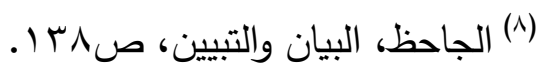

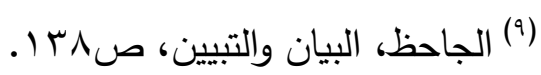

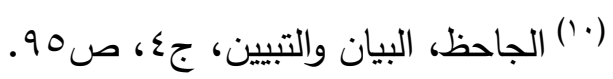

"'الجاحظ، الحيوان، الجزء الاول، تحقيق عبد السلام هارون، مطبعة مصطفى الحلبي،

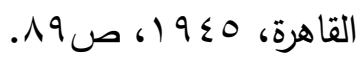


(') الجاحظ، الحيوان، ج)، تحقيق عبد السلام هارون، القاهرة، 0 (1) 1، ص. • 9.

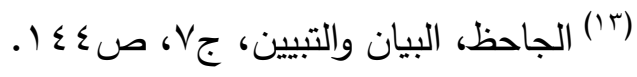

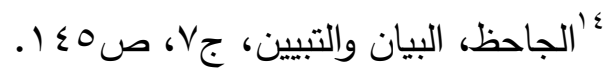

• علي أبو ملحم، في الجماليات نحو رؤية جديدة الى فلسفة الفن، بيروت، ،99 199، ص

(1) علي أبو ملحم، في الجماليات نحو رؤية جديدة الى فلسفة الفن، بيروت، 991،

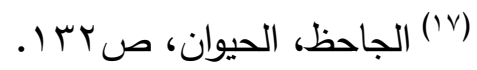

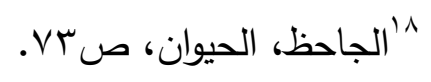

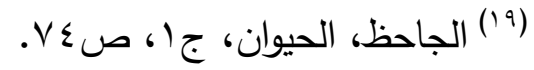

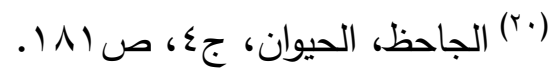

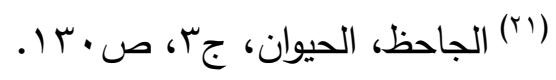

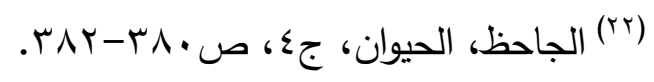

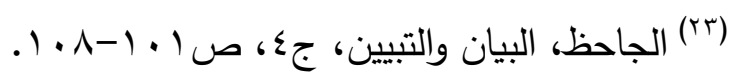

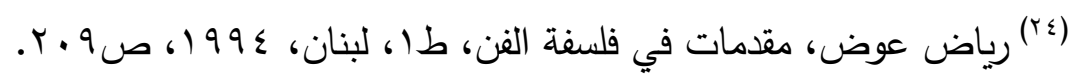

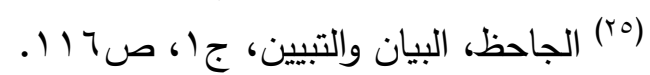

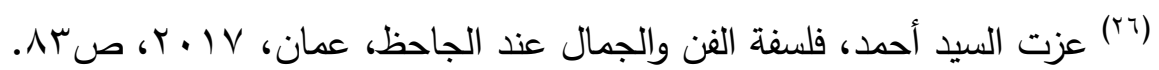

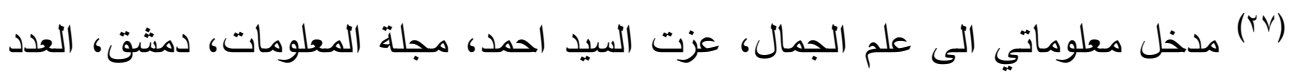

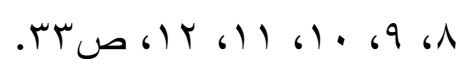

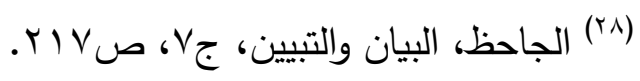

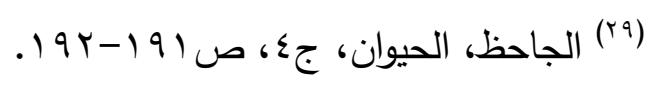

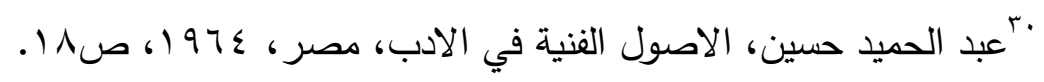

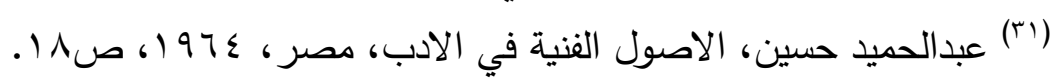

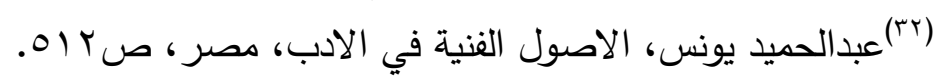




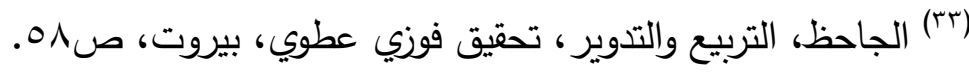

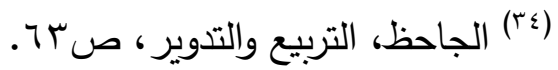

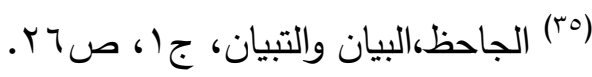

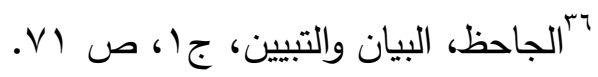

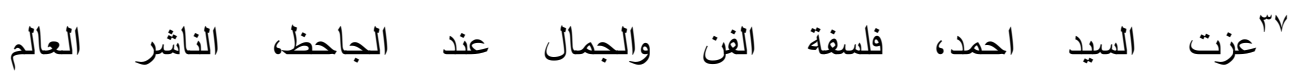

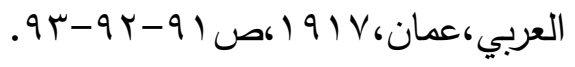

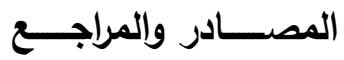

1- الجاحظ، البيان والتبين، تحقيق علي ابو ملحم، دار الفكر للجيمع، بيروت، 971 أ.

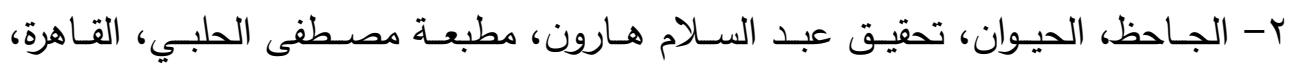
$.19 \leqslant 0$

r- الجاحظ، رسالة القيان، تحقيق عبد السلام محمد هارون، مكتبة الخانجي، القاهرة، \&97 أ. ع- الجاحظ، رسالة النساء، تحقيق عمر ابو النصر، مطبعة النجوى، بيروت، 1979 1.

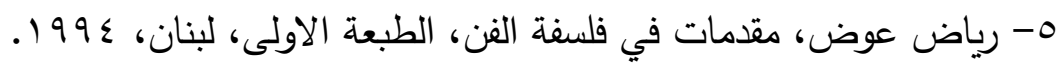

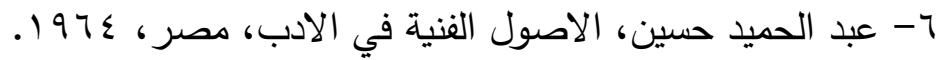

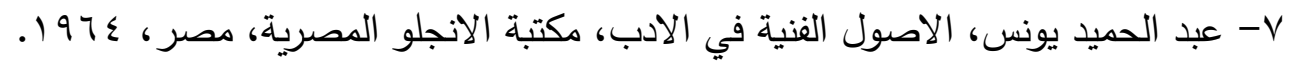

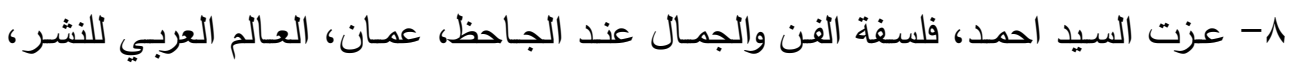
$. r . I V$

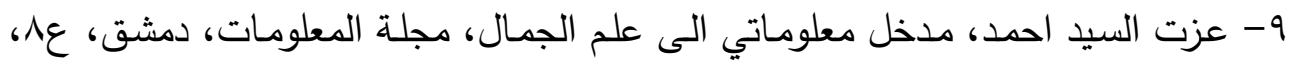
$.197461461161 \cdot 69$ • 1- علـي ابو ملحم، في الجماليات نحو رؤيسة جديدة الى فلسفة الفن، بيـروت، 
Sources and references:

I. Al-Jahiz, The Risalat Al-Qayan, Edited by Abd al-Salam

Muhammad Harun, al-Khanji Library, Cairo.

II. Al-Jahiz, The Women's Message, edited by Omar Abu Al-Nasr, Beirut, Al-Najwa Press, 1979.

III. Al-Jahiz Al-Hayyun, achieved by Abd Al-Salam Haroun, Mustafa Al-Halabi Press, Cairo $19 \leqslant 0$.

IV. Al-Jahiz Al-Bayan and Al-Tabeen An investigation by Ali Abu Melhem Beirut, Dar Al-Fikr for All, $194 \wedge$.

V. Ali Abu Melhem in Aesthetics towards a new vision for the philosophy of art, Beirut University Foundation 199.

VI. Riad Awad Introductions to the Philosophy of Art First Edition Lebanon $199 \varepsilon$.

VII. Al-Sayyid Ahmed attributed the philosophy of art and beauty to Al-Jahiz Amman Arab World for Publication Y. IV.

VIII.Mr. Ahmed attributed an informational introduction to aesthetics, Information Magazine, Damascus, to the numbers $\wedge 91$. II year 1994.

IX. Abdel Hamid Hussein, Artistic Origins in Literature, Egypt 197 ๕. X. Abdel Hamid Younes, Artistic Origins in Literature, Anglo-Egyptian Library, Egypt $197 \varepsilon$. 